\title{
Discursos populistas en la política española actual: el caso de Podemos y Ciudadanos
}

Esperanza R. Alcaide Lara

Universidad de Sevilla

\section{Introducción}

En España se ha llegado a una nueva era política, calificada por los medios como del cambio. Esta se inicia con la aparición de los llamados "partidos emergentes", que nacen en la situación de crisis económica y política que ha estado sufriendo el ciudadano, y que ha estado marcada por los casos de corrupción que afectan a los dos partidos mayoritarios, PP y PSOE. A ello, se une un hecho histórico: la tentativa de independencia de Cataluña a iniciativa del gobierno catalán.

Partidos como Ciudadanos (centro) o Podemos ${ }^{\mathrm{I}}$ (izquierdas) se erigen a sí mismos en regeneradores de una situación "catastrófica" para el ciudadano, con un discurso que recuerda mucho a los de conocidos líderes populistas europeos e hispanoamericanos ${ }^{2}$.

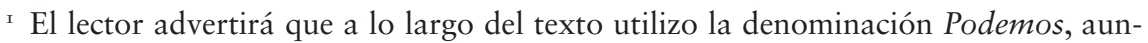
que en las tablas de análisis aparecen Unidos Podemos o las siglas U.P. Esto es debido a que diferenciamos el partido al que pertenece el agente político analizado (Podemos) de la coalición en nombre de la que actúa siendo diputado (Unidos Podemos, constituida por Podemos y sus llamadas Confluencias).

${ }^{2}$ El hecho de incluir a ambos dirigentes, y por ende a sus partidos, en la etiqueta "populista" se debe a que, en la sociedad en general, ambos han sido igualados en este sentido: "Xavier Casals afirma que las formaciones de reciente formación tienen un componente populista porque sus discursos son esencialmente anti-establishment y las nuevas denominaciones son 'inclusivas y transversales' (Ciutadans, Foro Asturias Ciudadano), con 'valores' (Unión Progreso y Democracia, Compromís) o con imperativos (Podemos, Ganemos), de tal forma que 'el enunciado es el programa'” (Carretero, 20I4).

Cómo citar este capítulo:

Alcaide Lara, E. R. 20I9. "Discursos populistas en la política española actual: el case de Podemos y Ciudadanos”. In: Françoise Sullet-Nylander, María Bernal, Christophe Premat \& Malin Roitman (eds.). Political Discourses at the Extremes. Expressions of Populism in Romance-Speaking Countries. Stockholm Studies in Romance Languages. Stockholm: Stockholm University Press, pp. 83-I04. DOI: https://doi.org/Io.I6993/ bax.e. License: CC-BY 
En este trabajo mi objetivo es analizar discursos de los dirigentes de ambos partidos, Albert Rivera y Pablo Iglesias, hoy con amplia representación en las Cortes Españolas, para delimitar si se ajustan a las características que Charaudeau (2009), entre otros, adjudicó a los discursos políticos populistas. Haremos un contraste entre las estructuras discursivas empleadas por ambos políticos, que tan buenos resultados electorales les han supuesto en las últimas campañas.

Metodológicamente, partimos de la siguiente afirmación de Charaudeau (2009: 260-26I), que enclavamos en el Análisis de Discurso:

el sentido que transmite un discurso depende del efecto que produce, dado que, en toda situación de comunicación, éste resulta del encuentro entre un sujeto hablante y un sujeto interpretante. [...]) El poder del lenguaje no está solamente en lo que dice, sino en lo que transmite.

Es el fenómeno de la significancia.

El corpus manejado está constituido básicamente por las intervenciones de Iglesias y Rivera recogidas en el Diario de Sesiones del Congreso de los Diputados $n^{\circ} 4$ de la XII Legislatura de las Cortes Españolas, perteneciente a la sesión de debate para la investidura de Mariano Rajoy como Presidente del Gobierno de España.

\section{El marco del discurso político y populista}

Según Charaudeau (2009), en el discurso político, el poder persuasivo de las palabras reside tanto en la fuerza del proyecto de idealidad social, el proyecto ideal que tiene en mente el político, del que son portadoras, como en su repercusión en la esperanza de los ciudadanos, sensibles a los valores, al carisma de las personalidades políticas y a la emoción situacional. Estas toman sentido a través de su enunciación, lo que hace que enfrentarse a un discurso político, y además juzgarlo como populista, obligue a analizarlo en el contexto socio-histórico en que aparece y en la situación de comunicación que genera cierto proceso enunciativo.

Para entender la relevancia de los actos persuasivos y sus efectos en la imagen del político, hemos de tener en cuenta las instancias comunicativas partícipes en el espacio público y, más concretamente, en el político. Siguiendo a Charaudeau (2009: 26I), la palabra proferida en el espacio público se mueve entre tres instancias: una de producción, una de recepción y una de mediación, y su sentido depende del juego que se establece entre ellas. 
La instancia de producción tiene carácter colectivo, pues, aunque esté encarnada por una sola persona, esta actúa siempre como representante de un grupo más o menos homogéneo (una institución, un partido, un sindicato, una asociación, una entidad informativa o comercial, etc.).

Por lo tanto está legitimada por una especie de contrato social de comunicación, ya sea en su derecho de elogiar un proyecto político (para hacer votar o defender lo propuesto), en su derecho de justificar o defender una idea (para hacer adherir la opinión pública), en su "derecho de informar" (para alimentar la opinión ciudadana), o bien en su derecho de elogiar un producto (para hacer comprar) (Charaudeau 2009: 26I).

Su actuación es absolutamente voluntaria, y su reto es su credibilidad y su capacidad de persuasión.

La instancia de recepción, dependiendo del tipo discursivo, en mi opinión, se presenta bajo diversas configuraciones, siendo, habitualmente, un público más o menos heterogéneo ${ }^{3}$. Según Charaudeau (2009), se erige en "destinatario-blanco" de una palabra que supuestamente lo implica según los objetivos que esta se marque: será beneficiario de un bien futuro de carácter político, social o comercial, o individuo amenazado por un peligro del que ha de protegerse. En ambos casos, «la instancia-blanco está ubicada en posición de deber creer que puede ser el agente de una búsqueda que le resultará beneficiosa» (Charaudeau 2009: 262).

En el espacio político, según este autor, la de recepción es una instancia ciudadana, con responsabilidad consciente en su papel de delegación de poder, y el derecho de observación de la acción política. En mi opinión, esta instancia está en la mente de todo político, incluso cuando parece que su destinatario es el partido adversario, pues el político está seguro de que sus adversarios físicos en el hemiciclo solo son los alocutarios $^{4}$ de un espacio teatralizado, el parlamento. A quien ha de llegar el enunciado, en las circunstancias de los discursos aquí analizados, es

${ }_{3}$ La heterogeneidad de esa instancia de recepción, que supone dirigirse a individuos con diversos niveles de instrucción, hace que la palabra que se desarrolla en el espacio público, según Charaudeau, haya de presentarse bajo el ropaje de la simplicidad, tanto en la sintaxis y el léxico, como en las estructuras argumentativas, "lo que conduce al orador a abandonar el rigor de la razón en favor de la fuerza de verdad de lo que está enunciando, diciendo no tanto lo que es verdadero, sino lo que él cree verdadero y que el otro debe creer verdadero" (2009: 262). Se trata no de la verdad, sino de la veracidad.

${ }^{4}$ Para los conceptos de locutorlalocutario y enunciador/destinatario, cf. Ducrot (I986: I93-2I7). 
al ciudadano (la gente que diría Iglesias, líder de Podemos), a quien el político no pierde de vista, sobre todo en un parlamento que parece en ese momento abocado a unas nuevas elecciones:

I. Este debate no va a cambiar lo que vamos a votar las 350 personas que ocupamos estos escaños, pero puede que lo escuche la gente verdaderamente importante, la que está afuera. (Iglesias, $2 \mathrm{I}^{5}$ )

2. Hay muchas familias que nos están viendo, en las que el padre, la madre, en definitiva, el núcleo familiar, está en el paro, y no tiene ingresos. [...] Otra novedad que muchos padres y madres que nos estén viendo seguro que querrán que se ponga en marcha en esta legislatura, la baja por maternidad [...]. (Rivera, 42)

Entre las instancias ya citadas, y con la función de ponerlas en contacto, se encuentra la de mediación:

es instancia de producción de una escenificación y construye por consiguiente una instancia destinataria que no coincide necesariamente con la precedente. Además, debe ser legitimada en su papel de transmisor de información, lo cual genera ciertas exigencias de responsabilidad (Charaudeau 2009: 262).

En el espacio político y, en concreto en el parlamentario, los medios de comunicación desempeñan un papel fundamental. Podemos hablar incluso de que actualmente tienen un gran peso social como aparato de (re)producción ideológica.

Dentro del espacio público, el político presenta una peculiaridad: a la instancia de producción, de recepción y de mediación, se le une la instancia adversa, el adversario político, que, en el debate parlamentario, desempeña el rol discursivo fundamental de alocutario, que rivaliza con la primera (instancia política de producción). Ambas desarrollan un juego de poder.

La siguiente imagen (Alcaide Lara, 20I7) representa gráficamente lo que hemos expuesto:

5 Los números que encontramos junto al nombre del locutor del fragmento discursivo corresponden a la página en que lo encontramos en la versión escrita del Diario de Sesiones anteriormente citado, al que pertenecen las intervenciones analizadas en este trabajo. 

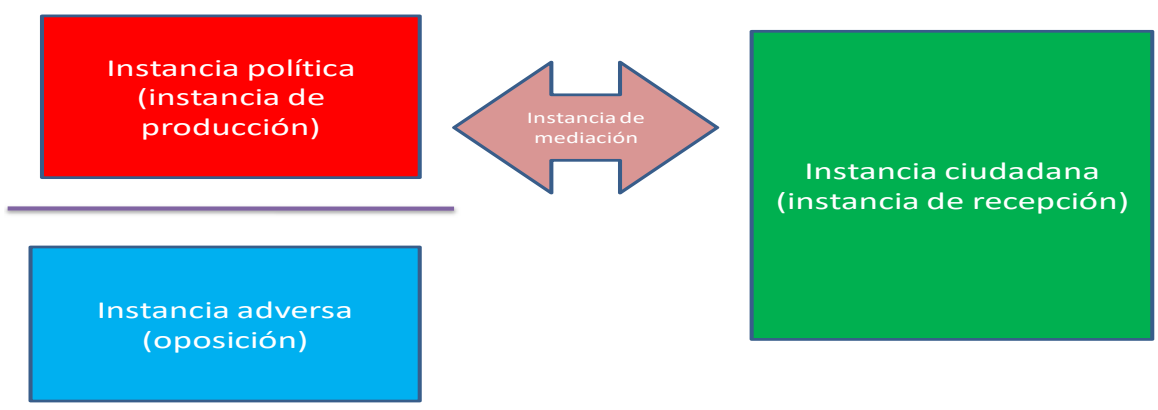

Figura 1. Representación del esquema comunicativo del discurso parlamentario. Copyright: Esperanza R. Alcaide Lara. License: CC BY

En este entramado, el político, para persuadir al ciudadano, debe poner en práctica estrategias comunicativas de imagen ${ }^{6}$, incidiendo en la veracidad, credibilidad y atractivo de su discurso, y buscando conmoverlo para lograr su adhesión?

\section{El discurso populista}

No podemos ocuparnos en este momento del concepto de populismo en sí mismo. Es notable, y de ello dan buena cuenta los investigadores ${ }^{8}$, la confusión que rodea a este término. Nos atendremos a las definiciones más comunes de este.

El populismo es, según el Dictionnaire Larousse, la «idéologie politique de certains mouvements de libération nationale visant à libérer le peuple sans recourir à la lutte des clases» ${ }^{9}$. En español, el término populismo entra en el Diccionario Manual de la Lengua Española de

${ }^{6}$ Cf. Hernández Flores (20I3) y Alcaide Lara (20I4).

7 Este escenario triádico (instancias política, adversa y ciudadana) se compone de tres momentos discursivos, a juicio de Charaudeau (2009: 263): «I) probar que la sociedad se encuentra en una situación social juzgada de desastrosa de la que el ciudadano es la primera víctima; 2) determinar la fuente del mal y su responsable (adversario); 3 ) anunciar finalmente qué solución puede ser aportada y quién puede ser su portador».

${ }^{8}$ Cf. Aboy Carlés, (200I).

9 Populisme (2017): http://www.larousse.fr/dictionnaires/francais/populisme/ 62624?q=populisme\#6I9I9 [consultado 25/ 03/20I7]. Somos conscientes de que no son las acepciones de los diccionarios las mejores fuentes para definir de forma científica lo que actualmente significa populismo, pero nuestra intención es ofrecer una definición cercana a la que maneja el ciudadano cuando los distintos políticos se acusan unos a otros de populistas. Es decir, la que forma parte de su acervo cotidiano. 
la Real Academia Española en I985 como "doctrina política que pretende defender los intereses y aspiraciones del pueblo" (s.v. populismo). Actualmente, el Diccionario de la Lengua Española lo define como «tendencia política que pretende atraerse a las clases populares» (s.v. populismo, http://dle.rae.es/?id=TfyMi6t [consultado 25/03/20I7].

El populismo es una forma de hacer política que busca alcanzar o influir en el poder y que, además, no es ajeno a la democracia ${ }^{\mathrm{IO}}$. Se ponen en práctica una serie de estrategias de conquista o ejercicio del poder en un marco democrático, pero de una manera exacerbada que da paso a la fascinación por un ideal. No obstante, tiene un halo de ilicitud. Más que un sustantivo que nombra una ideología o una forma de hacer política, populismo es una etiqueta que, incluso entre aquellos que, siendo expertos analistas como es Iglesias (politólogo), toma un valor insultante:

3) Solo mencionan a la Unión Europea y a la OTAN y apuestan por una errática y torpe estrategia de lucha contra el terrorismo basada en el populismo punitivo y en las intervenciones militares, que se han demostrado ineficaces. (Iglesias, 24)

Iglesias ataca a su adversario (el Sr. Rajoy, candidato a la Presidencia del Gobierno de España), tachándole de "populista” en algunas de sus actuaciones. Algo que debemos tener muy en cuenta a la hora de estudiar el discurso populista es la relación que, como en todo discurso, existe entre la palabra y la acción. Puede ocurrir que un discurso tildado de populista pueda esconder actos que no lo son, y actos que sí lo son podrían ocultarse en palabras no susceptibles de este calificativo. Sería interesante, pues, constatar si hay una correspondencia absoluta entre ambos. En nuestro caso, solo podremos constatar el grado de populismo en los discursos de ambos dirigentes, y observar si sus movimientos y actos discursivos se corresponden con los usos y prácticas lingüísticas reconocidas como propias del discurso populista por los especialistas (vid. Bolívar 2009 y 2013, o Charaudeau 2009, entre otros).

A pesar de los numerosos "apellidos" que los movimientos populistas han tenido a lo largo de su historia (nacionalistas, clasistas, neoliberales, etnicistas, etc.), estos tienen puntos en común, que comprobaremos si son compartidos por los partidos que centran este trabajo:

ro Laclau (I978), Dorna (2006), Charaudeau (2009), entre otros, defienden que el populismo es parte de la democracia, a pesar de que se asocie habitualmente a las dictaduras tanto de izquierdas como de derechas (de hecho, a manera de insulto en España, los políticos del PP acusan manifiestamente de populista a Podemos por su conexión con el gobierno de Chávez en Venezuela, para el que han trabajado sus dirigentes). 
I. Nacen siempre en una situación de crisis social (económica, identitaria y moral, de cambio de régimen político). Es el caso de Podemos $^{\text {II }}$ y Ciudadanos ${ }^{\mathrm{I} 2}$.

2. Presencia de un líder carismático fuerte, sin un programa político propiamente dicho, sino que promete romper con las prácticas del pasado y terminar con la corrupción y devolver su poder al pueblo. Salvo el aspecto del programa político, que sí tienen, al menos formalmente, ambos partidos, el resto de las características sí se da en Iglesias y Rivera. Iglesias es un ejemplo de ello a través de su discurso:

4) Llegamos aquí empujados por la gente, diciendo verdades como puños, y hoy constituimos un espacio político más amplio que reconoce la diversidad y la plurinacionalidad de nuestra patria y que, tarde o temprano, gobernará. Me enorgullece haber contribuido a hacerlo posible [...]. (Iglesias, 25)

II Podemos, partido político español de izquierdas, fundado en enero de 2014 y liderado por Pablo Iglesias. Nace del Movimiento I5 M, movimiento ciudadano formado a raíz de la manifestación del i 5 de mayo de 20 I I, convocada por diversos colectivos. Después de esta, unas cuarenta personas decidieron acampar en la Puerta del Sol de Madrid espontáneamente, como forma de protesta pacífica, con la intención de promover una democracia más participativa alejada del bipartidismo PSOE-PP y del dominio de bancos y corporaciones, así como una «auténtica división de poderes» con la intención de mejorar el sistema democrático.

Cuatro meses después de su formación, participó en las elecciones europeas de 20 I 4 , logrando cinco escaños (de 54) con el 7,98\% de los votos. Se convirtió en el cuarto partido más votado de España. En los primeros veinte días de inscripción, reunió más de I00 000 miembros, convirtiéndose en el tercer partido en número de afiliados, y en octubre ostentaba ya el segundo lugar, con más de 200000 . También llegó a aparecer como el primer partido del país en intención directa de voto, según las encuestas. En las elecciones generales (20 de diciembre de 20I 5), Podemos es la tercera fuerza política en el Parlamento.

I2 Ciudadanos (C's) nació de la plataforma cívica Ciutadans de Catalunya, creada el 7 de junio de 2005 en Barcelona por un grupo de quince intelectuales, profesores universitarios y profesionales de diversos campos. En su manifiesto titulado Por la creación de un nuevo partido político en Cataluña, se declararon opuestos a lo que consideraban como la imposición del nacionalismo catalán desde diversos ámbitos del poder en Cataluña, lo que calificaron como "nacionalismo obligatorio». El nuevo partido decidió denominarse Ciudadanos-Partido de la Ciudadanía, en castellano, con el fin de reafirmar que su ámbito de actuación es el de toda España, si bien en las comunidades autónomas con más de una lengua oficial se usa indistintamente el nombre en ambos idiomas oficiales. Con posterioridad, Albert Rivera, su líder, afirmó que escogieron la palabra «ciudadanos» como nombre del partido porque les gustaría ser «ciudadanos del mundo». 
Rivera se presenta como jefe de partido. Los folletos de su campaña lo erigen en líder carismático, al que se le atribuyen incluso frases de carácter sentencioso:

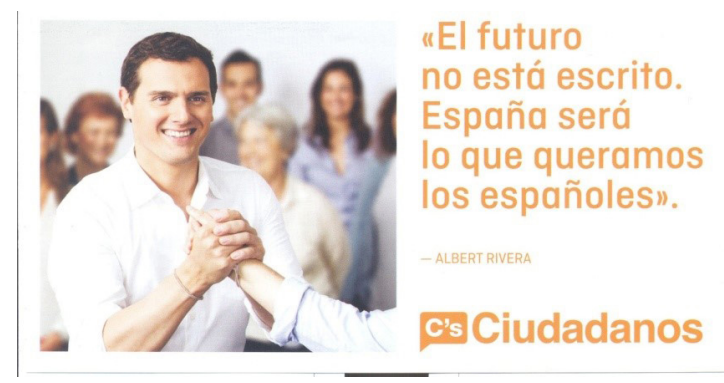

Imagen 1. Campaña electoral de Ciudadanos, Elecciones Generales Españolas 20I6. Copyright: Ciudadanos. Licence: CC B Y-NC-ND

3. El populismo no es ideológicamente homogéneo. En el propio Podemos, no hay una línea ideológica uniforme: a veces se han definido como marxistas, otras socialistas, o simplemente de izquierdas ${ }^{\mathrm{I} 3}$. Ciudadanos está próximo a la derecha por lo que respecta a la economía (liberalismo, cercanía con el mundo empresarial), pero cercano a la izquierda en los valores sociales (aborto, matrimonio entre personas del mismo sexo, etc.). La siguiente tabla resume lo anteriormente dicho:

Tabla 1. Rasgos comunes de actuación. Copyright: Esperanza R. Alcaide Lara. License: CC BY

\begin{tabular}{lll}
\hline Rasgos de actuación & Iglesias(UP) & Rivera $($ C’s $)$ \\
\hline Nace en una situación de crisis social & + & + \\
Presencia de un líder carismático fuerte & + & + \\
No homogéneo ideológicamente & + & + \\
\hline
\end{tabular}

${ }^{13}$ Entre sus filas tenemos a representantes más radicalizados (Pablo Iglesias mismo), izquierdistas más moderados (Íñigo Errejón), antiguos miembros de la coalición Izquierda Unida, ideólogos poco definidos (Juan Carlos Monedero), militares (como independientes, el caso de José J. Rodríguez, que, por instancias del Ministerio de Defensa, pasa a la situación de "retiro" del Ejército por comparecer a las elecciones en las filas de Podemos), y antiguos dirigentes de la extinta Alianza Popular -germen del actual PP, fundada por Manuel Fraga Iribarne, ministro de Francisco Franco- como Jorge Verstrynge. 


\section{Características del discurso populista}

Tanto en el populismo de izquierdas como en el de derechas, el discurso tiene un denominador común: una retórica simplista y esencialista, con fuerte base y contenido emocional en torno a temas como la inmigración, la violencia, la inseguridad, el paro en las familias, etc.

Igual que cualquier discurso, el populista utiliza estrategias persuasivas con el objetivo de captar al destinatario, pero valiéndose de factores simbólicos que afectan más a la emoción ${ }^{\mathrm{I} 4}$ que a la razón. En este sentido, uno de sus recursos más peculiares, el exceso de carácter emocional (quizás el que le separe del discurso político general), consigue atrapar al pueblo sin que este sospeche ${ }^{\mathrm{r}}$. Tanto Podemos como Ciudadanos hacen uso de este recurso. Iglesias a través de sus discursos y la escenificación de estos. Sin ir más lejos en la Sesión de Investidura (fallida) para la Presidencia del Gobierno Español, celebrada en el Congreso de los Diputados español el 2 de marzo de 2016 , cuyo candidato era el socialista Pedro Sánchez, Iglesias protagonizó dos episodios que pueden ejemplificar este aspecto: tras acabar su intervención, levanta el puño izquierdo, como los dirigentes y militantes de la izquierda en sus actos de partido, lo que no es normal en la cámara ${ }^{16}$. Y, tras este gesto, Iglesias y Domenech (portavoz de En Comú Podem, confluencia de Podemos en el Congreso español) emulan, tras terminar su intervención el segundo, el "beso" que, en I979, protagonizan dos líderes comunistas en el aniversario de la fundación de Alemania del Este como estado comunista: Breznev (URSS) y Honecker (RDA) ${ }^{17}$.

Rivera, más comedido, escenifica el "exceso emocional” a través de sus palabras:

5) [...] la verdad es que es un orgullo subir a esta tribuna y representar a tres millones y medio de españoles. Es un honor estar aquí, en esta casa donde han pasado tantas cosas de la historia de España, donde se han sentado

${ }^{14}$ Lo emocional es esencial para entender el éxito de la comunicación en la política de determinados líderes, así como de los regímenes populistas, algo ya señalado desde la retórica aristotélica hasta nuestros días (cf. Kienpointner 2008).

is Al respecto de la emoción en el discurso, Charaudeau afirma: «Recurrir a efectos emocionales es constitutivo de todo discurso político, pero toma un carácter particularmente exacerbado en el discurso populista» (Charaudeau 20II: I2).

${ }^{16}$ Puede visionarse esta imagen en el siguiente enlace https://www.elperiodico.com/es/ politica/20160302/discurso-iglesias-investidura-sanchez-4942600

${ }^{17} \mathrm{La}$ imagen la tenemos en el siguiente enlace del diario El País: https://elpais.com/ elpais/2016/03/02/tentaciones/I4569I6488_or7972.html 
hombres de Estado, donde ha habido debates importantísimos y donde se forjó el debate, el diálogo, la concordia, durante la transición. (Rivera, DSCD, II $3,34^{18}$ )

En este ejemplo, Rivera habla del "orgullo" de representar a esos millones de españoles que le han votado, del "honor" de estar sentado en un lugar lleno de historia, y hace referencia al papel de las Cortes, sede del Parlamento, en un momento histórico, el de la transición, que propició el paso, en paz, de una dictadura a la actual democracia española. Palabras cargadas de emoción y que intentan despertar la emoción en el interlocutor, que, en este caso, dado el carácter televisado del acto institucional, no es el adversario propiamente, sino la ciudadanía.

El discurso populista tiene un marco común de escenificación, que pasamos a estudiar en relación a los líderes que nos ocupan.

\subsection{Situación de crisis y victimización}

Se presenta una situación social de la que es víctima única y exclusivamente el pueblo. De esta forma, este manifestará un estado de fuerte insatisfacción y resentimiento, que será explotado por el populista con estrategias como:

- Hablar de la situación económica haciendo hincapié en las cargas sociales que pesan sobre las empresas, las situaciones de precariedad de los trabajadores (paro, despidos) y de la distancia cada vez mayor entre ricos y pobres, el empobrecimiento de la nación.

- Hablar de la decadencia moral de la nación, la pérdida de las referencias identitarias, la pérdida de civismo y el relajamiento del vínculo social.

- Victimización del ciudadano, víctimas de la inseguridad o el desamparo de las instituciones. Se trata de crear angustia en el ciudadano.

Ejemplos:

6) Que ustedes sigan gobernando será un desastre para la gente corriente. Con ustedes a los mandos del Gobierno ha aumentado el número de ciudadanos en riesgo de pobreza, así como el número de hogares que no llegan a

${ }^{18}$ Este ejemplo pertenece al Diario de Sesiones $n^{o} 3$ de la XI Legislatura. 
fin de mes y ya casi la mitad de las familias españolas no se pueden permitir ni siquiera una semana de vacaciones. (Iglesias, 22)

7) Este es un gran país, sin duda, [...] pero es un país que en el mundo globalizado tiene riesgos y oportunidades, y si nos quedamos quietos, si no nos movemos, [...] si dejamos que España se bloquee mientras otros avanzan, perderemos oportunidades; oportunidades de mejora, de modernización, de politicas sociales, de regeneración de reformas institucionales. (Rivera, 39)

Vemos que, a través de las estructuras en cursiva, en ambos casos, se hace referencia a situaciones de gran insatisfacción, de pobreza, no solo presente sino también futura en el caso de Rivera, que repercuten directamente en el ciudadano.

\subsection{La causa del mal y los culpables}

Se trata de denunciar a los culpables: la clase política y las élites aisladas del pueblo (patronal, ricos, empresarios... la "casta" de Iglesias), las instituciones que han perdido toda autoridad y la burocracia, fuente de todos los males:

8) Hablar de su gestión es hablar de corrupción; la corrupción está en los genes de su partido, señor Rajoy, desde que lo fundaran los exministros vinculados al más corrupto de los regímenes que han existido en España (Aplausos-Protestas). (Iglesias, 33)

9) Nuestra gente son las mujeres que tienen que sacar adelante solas a su familia o que tienen que atender sin ayudas, por culpa de su Gobierno, a un familiar dependiente. (Iglesias, 22)

ıо) En definitiva, que no se escapen aquellos que pagaron muy poquito, mucho menos de lo que dice la ley, lo que ha hecho que muchos otros tengan que pagar mucho. (Rivera, 4I)

La causa del mal, el culpable, suele designarse vagamente. Se le presenta oculto en las sombras, manejando a la sociedad a su antojo y a escondidas, acechando para atacar y provocar más víctimas sin compasión: la clase política, las élites económicas, los corruptos, los cobardes, los tecnócratas, los "lobbies", las mafias, los grupos de interés (los capitalistas), la oligarquía, los enemigos exteriores (la inmigración, los extranjeros, los refugiados, las grandes potencias). En esto Iglesias es un maestro, no así Rivera: 
I I) Seguro que si hoy se lo pusiéramos fácil, señor Rajoy, los señores del $I B E X 35$ dejarían de considerarnos unos peligrosos populistas y darían la orden de que se nos tratara mejor. (Iglesias, 22).

I2) Hablaba usted ayer de la soberanía, precisamente en el aniversario de la reforma constitucional del artículo I 35 que pactaron ustedes con el Partido Socialista sin consultar a los ciudadanos. Decía usted ayer que el derecho a decidir corresponde al pueblo español, cuando usted es responsable de haber entregado ese derecho a la señora Merkel y a los poderes financieros. (Iglesias, 22)

I3) Ustedes han naturalizado la corrupción como una forma de gobierno en la que mandan los que no se presentan a las elecciones. (Iglesias, 33)

Las instituciones son también culpables de lo que ocurre, porque alejan a los políticos de los problemas del ciudadano, del pueblo:

I4) En estos meses incluso nosotros mismos hemos experimentado cómo esta institución aleja a sus miembros de los problemas de la calle, pero, por suerte, la política no es solamente esto, señor Mariano Rajoy. (Iglesias, 2 I)

I 5$)$ Durante los últimos Gobiernos del señor Zapatero y del señor Rajoy en este último mandato, [...]) sobre todo no ha habido sensibilidad hacia algunas de las reformas y algunos de los asuntos que los españoles reclamaban. (Rivera, 38)

\subsection{La exaltación de valores propios}

Claros son los siguientes ejemplos, en los que tanto Iglesias como Rivera se presentan como representante de la clase de políticos que escucha al pueblo y que es inquebrantable en sus principios:

I6) Pero nosotros no somos así [...]: a nosotros no se nos compra, ni cedemos a las presiones ni a los insultos de los poderosos y sus asalariados. (Aplausos) Nadie, absolutamente nadie en España concibe la posibilidad de que nosotros vayamos a renunciar a nuestros principios y a faltar a nuestra palabra poniéndoselo fácil a usted. (Iglesias, 22)

I7) Los españoles votaron cambios, [...] y Ciudadanos lo entendió. Entendió que había que pedir cambios pero que no había cambios sin diálogos y sin acuerdos. (Rivera, 38 )

Al mismo tiempo, se hace hincapié en la falta de valores del contrario o adversario (enemigo): 
I 8) Tampoco hablan ustedes de los refugiados por los que habitualmente lloran lágrimas de cocodrilo sin cumplir jamás sus compromisos. (Iglesias, 24)

I9) Señor Rivera, ya se lo dije en un debate: usted no es de izquierdas ni de derechas; usted es de lo que haga falta y de lo que le ordenen desde arriba, porque usted no manda ni siquiera en su partido. Le iba a decir a usted que es la marioneta gatopardiana de las élites, pero creo que me entenderá mejor si le digo que es usted el chicle de MacGyver del régimen: vale usted para todo. (Aplausos). [...] Y es que lamento informarle que su papel en nuestra historia se está agotando. Ustedes nacieron para frenar el cambio y para ser la muleta de lo viejo. [...] me temo que la burbuja naranja se está desinflando y este intento de investidura fallida va a dejarles a ustedes ocupando el papel que les corresponde. Es lo que tiene ser el chicle de MacGyver: dura lo que dura. (Iglesias, 24)

20) Los españoles no se han equivocado, se equivocarán aquellas señorías que piensen con la calculadora electoral y en sus intereses de partido o, lo que es peor, en sus intereses personales. (Rivera, 38 )

Al igual que cualquier discurso político, el populista debe proponerse un proyecto de "idealidad social" en que se muestren valores que se suponen representantes de la base del vínculo que nos une como miembros de la comunidad social:

2 I) La respetabilidad no la da hacer trucos en el Parlamento ni tragarse los sapos que imponen los ricos. La respetabilidad en política la da poder mirar a tu gente a la cara y decirles: yo estoy aquí por ti y para ti. Nuestra gente es la gente corriente, la gente de los barrios y pueblos de este país de países (Rumores). Nuestra gente se levanta temprano a trabajar, a buscar trabajo, a sacar su pequeño negocio adelante. Nuestra gente son los jóvenes que han tenido que emigrar y los que se han tenido que quedar padeciendo el paro y la precariedad. Nuestra gente son las familias desahuciadas, los abuelos y abuelas que estiran su pensión para ayudar a sus hijos y a sus nietos. Nuestra gente son las mujeres que tienen que sacar adelante solas a su familia o que tienen que atender sin ayudas, por culpa de su Gobierno, a un familiar dependiente. (Aplausos). Nuestra gente son las maestras y maestros, los profesionales de la sanidad, los ciudadanos de uniforme que muchas veces se ven obligados a trabajar sin chalecos antibalas. Nuestra gente son los estudiantes sin becas. Y esa es la gente a la que queremos poder mirar a la cara con orgullo, y esa gente sabe, incluso si no nos vota, que nosotros no traicionamos nuestra palabra ni nuestros principios. (Iglesias, 22)

22) [...] yo les digo una cosa: no me veo capaz de mirar a los ojos a los españoles y decirles que por la política de la ejecutiva de mi partido, o por mi sillón, o por no sé qué carguillo, este país no se pone en marcha. (Rivera, 39) 
El populista se sumerge en la historia y en las tradiciones para dar con lo auténtico, lo verdadero, lo más puro. El objetivo es reconstruir la identidad destruida por la crisis, por el enemigo, identidad que reparará el mal existente, con lo que el pueblo recuperará su protagonismo. Un potente recurso en este sentido es hacer creer que todo es posible enseguida (ahora) y que el milagro del cambio es realizable, activándose la esperanza:

23) Nosotros no queremos la respetabilidad que da el reconocimiento de los poderosos; al contrario, como dijo el fundador del Partido Socialista, merecer el odio de los que envenenan al pueblo es la mayor de las honras. Y nosotros tenemos la suerte de que los poderosos nos honran cada día (Aplausos). (Iglesias, 22)

Es también característico de este tipo de discurso señalar medidas vagas para terminar con la crisis (entre otras, aumentos de penas carcelarias, bajadas de impuestos sin reparar en consecuencias, aumentos de salarios para trabajadores y funcionarios, menores cargas fiscales para las empresas), lo que incide en la exaltación de los valores propios. La diferencia entre Iglesias y Rivera es que el primero lo expone bajo el signo del miedo (si gobiernan ustedes, todo empeorará) y el segundo de la esperanza (si gobiernan con nuestro apoyo, todo cambiará), lo que también es lógico dado que, en el contexto del corpus analizado, uno es contrario a la investidura del candidato Rajoy y el otro está a favor para desbloquear el problema del (des)gobierno de España:

Tabla 2. Perspectivas desde la que tratan los temas los dos agentes. Copyright: Esperanza R. Alcaide Lara. License: CC BY

\begin{tabular}{ll}
\hline Iglesias & Rivera \\
\hline $\begin{array}{l}\text { Trata de forma explícita, pero } \\
\text { vaga, los temas que preocupan al } \\
\text { ciudadano bajo el signo del miedo: } \\
\text { Corrupción }\end{array}$ & $\begin{array}{l}\text { Trata de forma explícita, pero vaga, } \\
\text { los el signo de la esperanza: } \\
\text { Corrupción }\end{array}$ \\
$\begin{array}{l}\text { laborales } \\
\text { Políticas sociales (salario mínimo } \\
\text { interprofesional, plan de renta } \\
\text { garantizada, complemento salarial, } \\
\text { violencia de género) }\end{array}$ & Paro y reforma del modelo laboral \\
\end{tabular}




\begin{tabular}{ll}
\hline Iglesias & Rivera \\
\hline Pensiones & Educación \\
Sanidad pública gratuita & Reformas en el mundo judicial \\
Política territorial & Reforma del Senado y otras institucio- \\
& nes para recortar la burbuja política \\
Los refugiados & Pérdida de oportunidades por el \\
& bloqueo del gobierno \\
La inmigración & Premio a las energías limpias. No al \\
& impuesto al sol \\
& Persecución del fraude \\
\hline
\end{tabular}

\subsection{El líder}

El líder proyecta una imagen de autenticidad, transparencia y potencia, que se traduce en actuaciones contundentes, irónicas, no exentas de insultos, y posturas contrarias a todo lo que ha significado una mala praxis de los adversarios, y, por supuesto, al servicio del pueblo: romperá con el pasado y salvará a la sociedad.

24) Llegamos aquí empujados por la gente, diciendo verdades como puños, y hoy constituimos un espacio político más amplio que reconoce la diversidad y la plurinacionalidad de nuestra patria y que, tarde o temprano, gobernará. Me enorgullece [...] que, a pesar de todas las dificultades, en mi país haya hoy una opción política con posibilidades de gobernar que se enfrente a ustedes, señor Rajoy. (Iglesias, 25$)^{19}$

25) $\mathrm{Y}$ les digo una cosa: quien aspire a ser presidente de su país -y yo aspiro a serlo- no puede ser un obstáculo para su país [...] el cambio ha llegado al Congreso y estoy convencido de que algún día llegará al Gobierno (Aplausos). (Rivera, 40)

El proceso que sigue el líder en su discurso es:

Estigmatización de un mal $\rightarrow$ purificación $\rightarrow$ milagro: transformación inmediata de la realidad social.

19 En este ejemplo, podemos observar incluso ese proceso de polarización social de la que hablan Chumaceiro (2006) o Bolívar (2013) con respecto al discurso chavista en Venezuela. Rivera pretende una sociedad plural, no polarizada, consecuencia lógica de su posición en este debate: "Yo quiero jugar a unir los puntos, porque diferencias en una democracia siempre las habrá; es más, es sano, es bueno que haya diferencias" (Rivera, DSCD, I 2, 4, 39). 
26) En la última legislatura el Partido Popular indultó, por ejemplo, a los corruptos del caso Treball, de Unió, y nosotros no estamos de acuerdo con esa política. Por eso obligamos también al Partido Popular a firmar y acabar con los indultos, porque habían indultado también por corrupción política. También con los aforamientos del Gobierno y del Legislativo. En definitiva, los privilegios ante la justicia no los queremos ni para nosotros. Por eso lo hemos firmado y queremos que todo el mundo vaya al juez natural y no tenga privilegios ante la justicia. (Rivera, 44)

Gráficamente:

Tabla 3. Proceso del discurso del "líder". Copyright: Esperanza R. Alcaide Lara. License: CC BY

\begin{tabular}{lll}
\hline $\begin{array}{l}\text { Estigmatización de } \\
\text { un mal }\end{array}$ & Purificación & $\begin{array}{l}\text { Milagro: transforma- } \\
\text { ción inmediata de la } \\
\text { realidad social }\end{array}$ \\
\hline $\begin{array}{l}\text { En la última legisla- } \\
\text { tura el Partido Popular }\end{array}$ & $\begin{array}{l}\text { Por eso obligamos tam- } \\
\text { indultó, por ejemplo, }\end{array}$ & $\begin{array}{l}\text { En fefinitiva, los pri- } \\
\text { vilegios ante la justicia }\end{array}$ \\
$\begin{array}{l}\text { a los corruptos del } \\
\text { caso Treball, de Unió, }\end{array}$ & $\begin{array}{l}\text { indultos, porque habían } \\
\text { indultado también por }\end{array}$ & $\begin{array}{l}\text { po los queremos ni } \\
\text { eso lo hemosotros. Por }\end{array}$ \\
$\begin{array}{l}\text { y nosotros no estamos } \\
\text { de acuerdo con esa }\end{array}$ & corrupción política. \\
política. & $\begin{array}{l}\text { También con los afora- } \\
\text { mientos del Gobierno y }\end{array}$ & $\begin{array}{l}\text { y queremos que todo } \\
\text { el mundo vaya al juez }\end{array}$ \\
& nel Legislativo. & vilegios ante la justicia. \\
\hline
\end{tabular}

\subsection{Resultados}

Lo dicho se refleja gráficamente en la siguiente tabla:

Tabla 4. Escenarios compartidos por los dos agentes. Copyright: Esperanza R. Alcaide Lara. License: CC BY

\begin{tabular}{lll}
\hline Escenarios del discurso populista & Iglesias (UP) & Rivera (C's) \\
\hline Situación de crisis y victimización & + & + \\
Causa del mal y culpables & + & + \\
Exaltación de valores propios & + & + \\
Denostación de la falta de valores del adversario & + & + \\
El líder: "el representante del pueblo". & + & + \\
\hline
\end{tabular}




\section{La retórica populista}

Podemos resumir las características más generales de la retórica populista encaminada a conmover, mediante el empleo de fórmulas destinadas a captar al ciudadano en los siguientes puntos:

- Registro sencillo y comprensible.

- Estilo no estereotipado, con marcas originales.

- Uso y abuso de las nominalizaciones.

- Modalidades que expresan evidencia.

- Palabras que remiten al miedo, la decadencia, la desesperación o a la esperanza.

- Argumentaciones reducidas a la relación causa efecto.

- Práctica de la amalgama en la descripción de los actos de agresión mezclando actos mayores y actos menores, las causas con las desgracias.

- Recurrencia a cifras y porcentajes para respaldar sus palabras sin posibilidad de verificación.

Ejemplos de esto los tenemos en la forma en la que Iglesias nombra al pueblo (la gente, la calle), cómo se dirige a sus adversarios ${ }^{20}$, o el léxico popular empleado (casi vulgar, poco adecuado para el escenario en que se mueve $)^{2 \mathrm{~T}}$. Las intervenciones con tintes humorísticos son también frecuentes en ambos políticos:

27) Este hombre le decía a mi amigo periodista que si los de Unidos Podemos queríamos ganar en respetabilidad, deberíamos facilitar su investidura, señor Rajoy. No se alboroce usted, no vamos a seguir la recomendación de este hombre. (Iglesias, 2I-22)

${ }^{\circ}$ A Ciudadanos los llama la naranja mecánica; con Rajoy, candidato a la presidencia, utiliza formas de tratamiento peyorativas e ironizantes: "la política no es solamente eso, señor Mariano Rajoy" (Iglesias, 2I). Con bastante frecuencia cae incluso en el insulto, lo que empobrece el diálogo democrático. Sobre este aspecto dice Bolívar (2009: 32): "toda transformación o cambio es posible en gran parte gracias a la palabra que, en el diálogo democrático, debe ser respetuosa del otro, de su imagen personal, política y cultural. La lucha por el poder pasa por el discurso y los modelos políticos, dominantes o no, se construyen con la palabra» Sobre el insulto en el discurso político, cf. Fairclough (2000), Martín Rojo (2000), Ilie (200I) y Bolívar (2009 у 2013).

${ }^{21}$ «Espero de corazón que su cabreo no fuera una sobreactuación» (22) o "y además no recogen medidas para evitar las muertes en el tajo» (23). 
28) Yo sé que usted es más partidario de hombres de Estado como Otegi ${ }^{22}$, pero yo soy mucho más partidario de hombres de Estado como Suárez ${ }^{23}$ y González (Aplausos). (Rivera, 44)

Otro aspecto es el posicionamiento del orador populista: la imagen proyectada de un Yo que se afirma potente, voluntario y comprometido, representado a menudo por un Nosotros que incluye al líder y a su partido y partidarios. A veces prefiere referirse a sí mismo bajo la tercera persona de "teatralización”, autodesignándose como el protagonista de una acción salvadora:

29) (Señor Sánchez) no sé si recuerda usted que desde esta tribuna le advertí de los peligros de la "hipoteca naranja" ${ }^{4}$ (Rumores). Supongo que estará de acuerdo conmigo en que no han sido los socios más fiables ni más leales a la vista de lo que estamos viendo hoy. (Iglesias, 25)

30) Usted sabe que vamos a votar contra su candidatura y sabe que nos va a tener enfrente siempre, pero hoy quiero recordarle por qué. Ayer se atrevió usted a reivindicar la soberanía y el constitucionalismo; usted, que representa a un partido fundado por ministros de una dictadura cuya fundación de pensamiento se llamó durante años Cánovas del Castillo (Rumores), una respetable figura que despreciaba el sufragio universal. Usted, líder de la tradición conservadora que arranca en el ¡Vivan las caenas!, habló ayer de I 8 I 2. Usted no es de la Pepa ${ }^{25}$, señor Rajoy, ni de ninguna Constitución. Usted es más de la carta otorgada, otorgada por la señora Merkel (Aplausos). (Iglesias, 22)

3 I) Me indignó escucharle decir ayer que hace falta un Gobierno que tranquilice a los inversores y a los socios europeos. Lo que hace falta es un Gobierno que dé la cara por la gente, señor Mariano Rajoy. (Aplausos) (Iglesias, 24)

${ }_{22}$ Arnaldo Otegi, conocido dirigente de Herri Batasuna, brazo político de la banda terrorista ETA.

${ }_{23}$ Adolfo Suárez, expresidente del Gobierno de España, considerado el gestor de la transición española de la dictadura franquista a la actual democracia.

${ }^{24}$ Con "hipoteca naranja", Iglesias hace un juego de palabras, utilizando el nombre del producto ofertado por la entidad ING Direct, el concepto hipoteca y el color naranja que identifica a la formación política Ciudadanos, para hacer referencia a las cargas que le supondría a Sánchez, candidato a la presidencia del Gobierno de España, el apoyo de Rivera (Ciudadanos).

25 Así se nombra a la Constitución de I8 I2, aprobada en Cádiz el I9 de marzo de ese año. Este día se celebra la festividad de San José, cuyo diminutivo es el masculino Pepe y el femenino Pepa. De ahí que se nombre como la Pepa. 
32) Por eso, señorías, no subo a esta tribuna, como otros, para hacer de comentaristas de la realidad, de comentaristas del verano. Este verano algunos han estado comentando la realidad -a pesar de ser ya diputados y no solo activistas- $y$ otros nos hemos dedicado a trabajar [...]. (Rivera, 38 )

Se hace uso de fórmulas contrastivas, para señalar las diferencias entre nosotros y los adversarios, la idea No somos iguales:

33) Algunos de nosotros irrumpimos en la política española sin estar en esta Cámara y quizás por eso comprendemos que lo verdaderamente importante está ahí fuera (la gente) ${ }^{26}$. (Iglesias, 2I)

34) Esa es la diferencia entre los gurús que venden humo y los que somos capaces de proponer políticas sociales que se pueden pagar. (Rivera, 40 )

El populista es desmesurado incluso en la producción corporal, vocal y gestual, que casi se puede calificar de barricada:

35) A muchos de ustedes les ofendió que alguno de nosotros levantáramos el puño en esta Cámara, que por tanto tiempo fue sumisa a la corrupción, a la mentira y a la cobardía. Hay símbolos que para ustedes son viejos. Yo pienso, como Carlo Levi, que el futuro tiene el corazón antiguo y que hay gestos que rinden homenaje a lo mejor de nuestra historia, de nuestra patria y de nuestros pueblos. Ayer se conmemoraba el Día Internacional de los Desaparecidos, y España encabeza el siniestro ranquin europeo en número de fosas comunes; en el mundo solo nos supera Camboya. Que no triunfe nunca el olvido: porque fueron somos, porque somos serán (El señor Iglesias Turión levanta el brazo derecho con el puño cerrado.- Aplausos de las señoras y los señores diputados del Grupo Parlamentario Confederal de Unidos Podemos- En Comú Podem - En Marea, puestos en pie). (Iglesias, 25)

Lo observado en nuestro corpus nos lleva a los siguientes resultados:

Tabla 5. Rasgos lingüísticos presentes en los discursos de Iglesias y Rivera. Copyright: Esperanza R. Alcaide Lara. License: CC BY

\begin{tabular}{lll}
\hline Rasgos lingüisticos & Iglesias (UP) & Rivera (C’s) \\
\hline Registro sencillo y comprensible & + & + \\
Estilo no estereotipado & + & +
\end{tabular}

${ }_{26}$ "Una estrategia muy productiva del discurso populista es la de presentar al líder como un político poderoso cuya fuerza proviene del pueblo hasta el punto de fundirse en una sola 'alma'” (Bolívar 20I3: I 45). 


\begin{tabular}{lll}
\hline Rasgos lingüísticos & Iglesias (UP) & Rivera (C’s) \\
\hline Uso abusivo de las nominalizaciones & + & - \\
Modalidades que expresan evidencia & + & + \\
Palabras que remiten a emociones & + & - \\
Registro familiar (vulgar) & + & - \\
Argumentaciones reducidas a causa efecto & $+/$ & $+/-$ \\
Práctica de la amalgama en la descripción & + & + \\
Recurrencia a cifras y porcentajes sin & - & - \\
verificación & & \\
Posicionamiento del orador (líder potente) & + & + \\
Producción corporal, vocal y gestual de mitin & + & - \\
\hline
\end{tabular}

\section{Conclusiones}

Ni la escenificación ni los escenarios de ambos oradores españoles distan mucho en la práctica discursiva de Podemos y Ciudadanos, los dos nuevos partidos, o partidos emergentes en España. En este sentido, si Iglesias se muestra más identificado con el pueblo, la gente, la "idealidad social (yo y el pueblo), y recurre más a la historia para defender actitudes puras, Rivera hace más hincapié en su misión de político que va a velar por el bien, que va a conseguir erradicar la corrupción, y que va a restablecer el bienestar social. De ahí que, según estos datos, si el discurso de uno es populista, el del otro, por tanto, también, y viceversa. Pero habrá que preguntarse si estos rasgos no son comunes al discurso político general actual, al menos en España.

Sí se diferencian en los rasgos que hemos dado en llamar "más puramente lingüísticos". No en vano, Rivera, abogado de profesión, y maestro en la Oratoria, ha sido reconocido como el político español actual que mejor comunica. Su estilo es tranquilo, pausado y correcto, a la vez que cercano. En cambio, Iglesias, polítologo, profesor de Universidad, hace gala de unos usos lingüísticos más cercanos a lo electoralista o propagandístico que a lo parlamentario. En este sentido, volvemos a las palabras del principio: El poder del lenguaje no está solamente en lo que dice, sino en lo que transmite (Charaudeau 2009). Según esto, ambos políticos comparten un trasfondo discursivo populista, pero Iglesias lo evidencia más en sus formas, mucho más exacerbadas y excesivas, que Rivera, más distanciado como comunicador en su rol de político. Rivera proyecta una imagen de político que trabaja para el 
ciudadano y por el ciudadano; Iglesias quiere ser el pueblo que trabaja para el pueblo. Esto es lo que nos dicen (transmiten) sus palabras.

\section{Referencias}

Aboy Carlés, G. (200I). "Repensando el populismo" XXIII Congreso Internacional Latin American Studies Association, Washington D.C., 6 al 8 de septiembre de 200I. http://lasa.international.pitt.edu/Lasa200I/ AboyCarlesGerardo.pdf

Alcaide Lara, E. R. (20I4). "La relación argumentación-(des)cortesía en el discurso persuasivo". Sociocultural Pragmatics 2 (2), 223-26I.

Alcaide Lara, E. R. (20I7). “'Invitar' en el discurso parlamentario: la atenuación como 'trampa'”. Lingüística Española Actual 39 (2), I77-I97.

Bolívar, A. (2009). "'Cachorro del imperio' versus 'Cachorro de Fidel': los insultos en la política latinoamericana”. Discurso \& Sociedad 2(I), I-38.

Bolívar, A. (20I3). "La construcción discursiva de la revolución bolivariana. Polarización y manipulación en la campaña electoral de 20I2". Temas de Coyuntura 67, I3 I-I63.

Carretero, R. (20I4). “QQué es el populismo y quién es populista en España?” (http://www.huffingtonpost.es/20I4/o9/2 I/populismos_n_5809776.html) [consultado I4/05/2016].

Charaudeau, P. (2009). "Reflexiones para el análisis del discurso populista". Discurso y Sociedad 3(2), 253-279.

Charaudeau, P. (20II). "Las emociones como efectos del discurso". Versión 26, 97-I I 8.

Chumaceiro, I. (2006). "Bolívar en el discurso de toma de posesión de tres presidentes venezolanos”, en M. Sedano, A. Bolívar \& M. Shiro (comps.), Hacer lingüística. Homenaje a Paola Bentivoglio. Caracas: Universidad Central de Venezuela, 645-655.

Dictionnarie Larousse: http://www.larousse.com/es/diccionarios/frances [consultado 25/03/20I7].

Dorna A. (2006). Médiatiques 38, Bulletin d'information de l'Observatoir du récit médiatique, Louvain-la-Neuve.

Ducrot, O. (I986). El decir y lo dicho. Polifonía de la enunciación. I. Agoff (tr.) Buenos Aires: Paidós.

Fairclough, N. (2000). "Dialogue in the public sphere", en S. Sarangi \& M.Coulthard (eds.), Discourse and Social Life. London: Longman, I 70- I 84. 
Hernández Flores, N. (20I3). “Actividad de imagen: caracterización y tipología en la interacción comunicativa”. Sociocultural Pragmatics I(2), I75-I98.

Hernández Flores, N. (20I4). "Imagen individual, imagen de grupo y la imagen de los otros en la construcción de una identidad política: el discurso del candidato español Pablo Iglesias”. Workshop Political discourse in Romancespeaking countries: linguistic and social science perspectives (ROMPOL I), 9-I I/IO/20I4. Universidad de Estocolmo.

Ilie, C. (200I). "Unparliamentary language: insults as cognitive forms of ideological confrontation”, en R. Dirven, R. Frank \& C. Ilie (eds.), Language and ideology II. Descriptive cognitive approaches. Amsterdam: John Benjamins, 235-263.

Kienpointner, M. (2008). "Impoliteness and emotional arguments". Journal of Politeness Research 4 (2), 243-265.

Laclau, E. (I978). Política e ideología en la teoría marxista. México, Siglo XXI.

Martín Rojo, L. (2000). "Enfrentamiento y consenso en los debates parlamentarios sobre la política de inmigración en España”. Oralia 3, I I3-I48.

Montero, M. (2003). "Retórica amenazante y crisis de gobernabilidad en Venezuela". Discurso y Sociedad 4(3), 37-56.

Real Academia Española (2017). Diccionario de la Lengua Española [versión en línea: http://dle.rae.es]. 